\title{
DE GORDELHAAK: EEN NUTTIG SIERAAD
}

Naar archeologische vondsten te oordelen, zijn kleding- of gordelhaken (daigou in het Chinees) in China in zwang gekomen tijdens de Oostelijke Zhou-periode (770-222 v.Chr.), en zijn ze in de loop van de Han-dynastie weer uit het repertoire van nuttige kledingacessoires verdwenen. Na ca 200 n.Chr. worden vrijwel alleen nog onpraktisch grote en overdadig versierde exemplaren aangetroffen, met een kennelijk meer symbolische of decoratieve functie in plaats van praktische gebruikswaarde.

Het type waarvan het Rijksmuseum er twee bezit, met de kenmerkende langwerpige knotsvorm (afb. 1 en 2), was door zijn uitvoering in kleurrijk ingelegd brons zeker een sieraad, maar tegelijkertijd puur praktisch. Deze haken werden gebruikt om de broek aan te gorden, of ook om de gordel rond de meer "typisch Chinese" lange gewaden (die voor de betere standen in deze zelfde tijd in gebruik komen) dicht te gespen. Met de ronde knop aan de onderzijde werd het voorwerp in de gordel vastgezet, en de omhoog krullende haak aan het smalle uiteinde greep dan in (een gaatje in) het andere eind van de gordel. ${ }^{1}$

\section{Hoe werd een gordelhaak gebruikt}

Maar hoe een gordelhaak gebruikt werd, is aan het uit zijn context gehaalde voorwerp zèlf eigenlijk niet zo op het eerste gezicht af te lezen. De toeschouwer wordt daarbij ook nog eens op het verkeerde been gezet, doordat de daigou meestal verticaal "staand" worden tentoongesteld en afgebeeld, ${ }^{2}$ terwijl dit type haak uiteraard horizontaal, in lijn met de gordel, werd bevestigd. (Vandaar ook de lichte kromming in de afgeplatte onderzijde - met de buik mee.) In grafsculptuur of andere afbeeldingen van menselijke figuren is echter U. heel af en toe een glimp te zien van de gordelhaak in functie - tenminste wanneer de handen van de mens in kwestie niet, zoals meestal, op ook weer typisch Chinese wijze voor de buik gevouwen of in de mouwen gestoken zijn. In afbeeldingen $3 a$ en $3 b$ is dat niet het geval, dankzij het feit dat beide deze bronzen beeldjes de sokkel zijn voor een olielamp (in de uitsnedes hier niet zichtbaar) die zij met wijd gespreide armen omhoog tillen. In beide gevallen is duidelijk te zien hoe het knotsvormige deel over de buik bolt, dan even verdwijnt, waarna het haakje een eindje verder weer door (het andere

Afbeelding 1 Cordelhaak, brons ingelegd met goud en zilver $2,5 \times 22,5 \times 2,5 \mathrm{~cm}$. China; Oostelijke Zhou, Strijdende Staten-periode, $5^{e}-4^{e}$ eeuw v.Chr. Rijksmuseum, inv.nr. AK-MAK-22 uiteinde van) de gordel omhoog steekt.

De soldaat uit het leger van de Eerste Keizer van Qin, waarvan afbeelding $3 c$ een detail toont, wordt soms aangeduid als een vuistvechter en soms als boogschutter - maar hoe dan ook staat hij in een positie klaar voor actie, en zijn daardoor zijn armen uit de weg. Dit ziet er uit als een iets ander type gordelhaak, met een korter, schildvormig versierd deel in plaats van de lange knots (en waarbij het bovendien lijkt alsof het de ronde knop is die naar boven door de gordel steekt, in plaats vann eent haakm - maar dal kann aan dé 


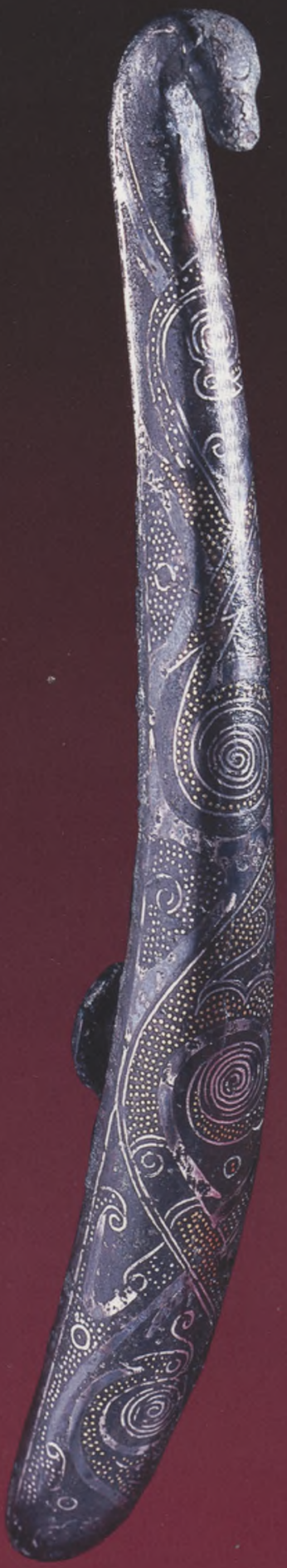



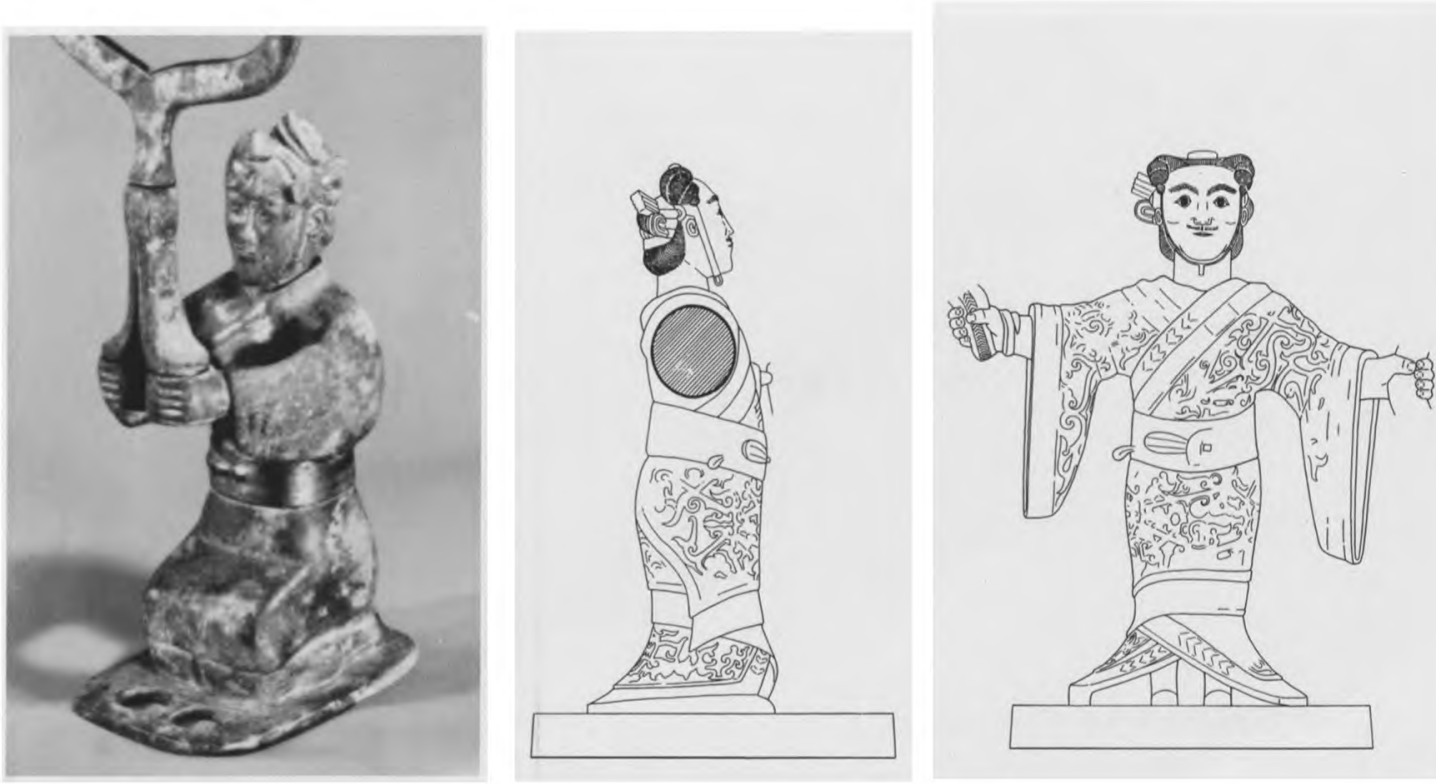

\begin{tabular}{|c|c|}
\hline Afbeelding 2 (links) & Afbeelding $3 a$ (linksboven) \\
\hline Gordelhaak, brons & Olielamp gedragen door geknielde \\
\hline ingelegd met goud en & figuur (detail), brons met resten van \\
\hline zilver & lakbeschildering \\
\hline $1,6 \times 14 \times 1,9 \mathrm{~cm}$ & h. $48,9 \mathrm{~cm}$. \\
\hline China; Strijdende Staten & China, provincie Henan, Sanmenxia; \\
\hline - Westelijke Han- & Strijdende Staten-periode, $4^{e}-3^{e}$ eeuw v.Chr. \\
\hline periode, ca $3^{e}$ eeuw & Uit: H. Brinker en R. Coepper, Kunstschatze \\
\hline v.Chr. & aus China, tentoonstellingscat. Kunsthaus \\
\hline Rijksmuseum, inv.nr. & Zürich, 1980, p. 99 \\
\hline
\end{tabular}

Afbeelding 2 (links) Gordelhaak, brons ingelegd met goud en zilver

$1,6 \times 14 \times 1,9 \mathrm{~cm}$ China; Strijdende Staten

Westelijke Han

v.Chr.

AK-MAK-24

\author{
Afbeelding $3 b$ \\ Zij- en vooraanzicht olielamp-drager van \\ ingelegd brons (detail), uit graf M6 van de \\ heersers van Zhongshan \\ China, provincie Hebei, Pingshanxian; \\ Strijdende Staten-periode, ca. $4^{e}$ eeuw \\ v.Chr. \\ Tekening uit: Das alte China: Menschen \\ und Cötter im Reich der Mitte, \\ tentoonstellingscat. Kulturstiftung Ruhr, \\ Essen, 1995, afb. 65:2
}

foto of verlies aan detaillering in het beeld liggen. De beschadiging precies op de grens van het ene uiteinde van de riem en het versierde schildje helpt ook niet mee.) Kortere haken met een schildvorm zijn ook bekend, ${ }^{3}$ maar hiervan wordt tegenwoordig meestal gedacht dat ze bedoeld waren om verticaal gebruikt te worden. Wel bevestigd met de knop door de gordel, maar met de haak los naar beneden, dus om iets (een mes of een buideltje o.i.d.) aan het haakje aan de riem te hangen. De gordelhaak van deze Qin-soldaat zou dat dan misschien kunnen tegenspreken.

Andere typen haken, van het schild-model maar ook in andere vormen - die wel een knop aan een kant hebben, en een haakje de andere kant op wijzend, maar die in het algemeen kleiner zijn en niet zo'n langgerekte gebogen knotsof staaf-vorm vertonen - waren waarschijnlijk bedoeld om andere delen van de kleding aan of om te gespen. De plaats in het graf waar ze zijn aangetroffen geeft dat soms al aan: naast het hoofd voor een hoofdtooi, bijvoorbeeld. Het lijkt een goede suggestie om het gehelle verschijijnsef te benoemenn and 


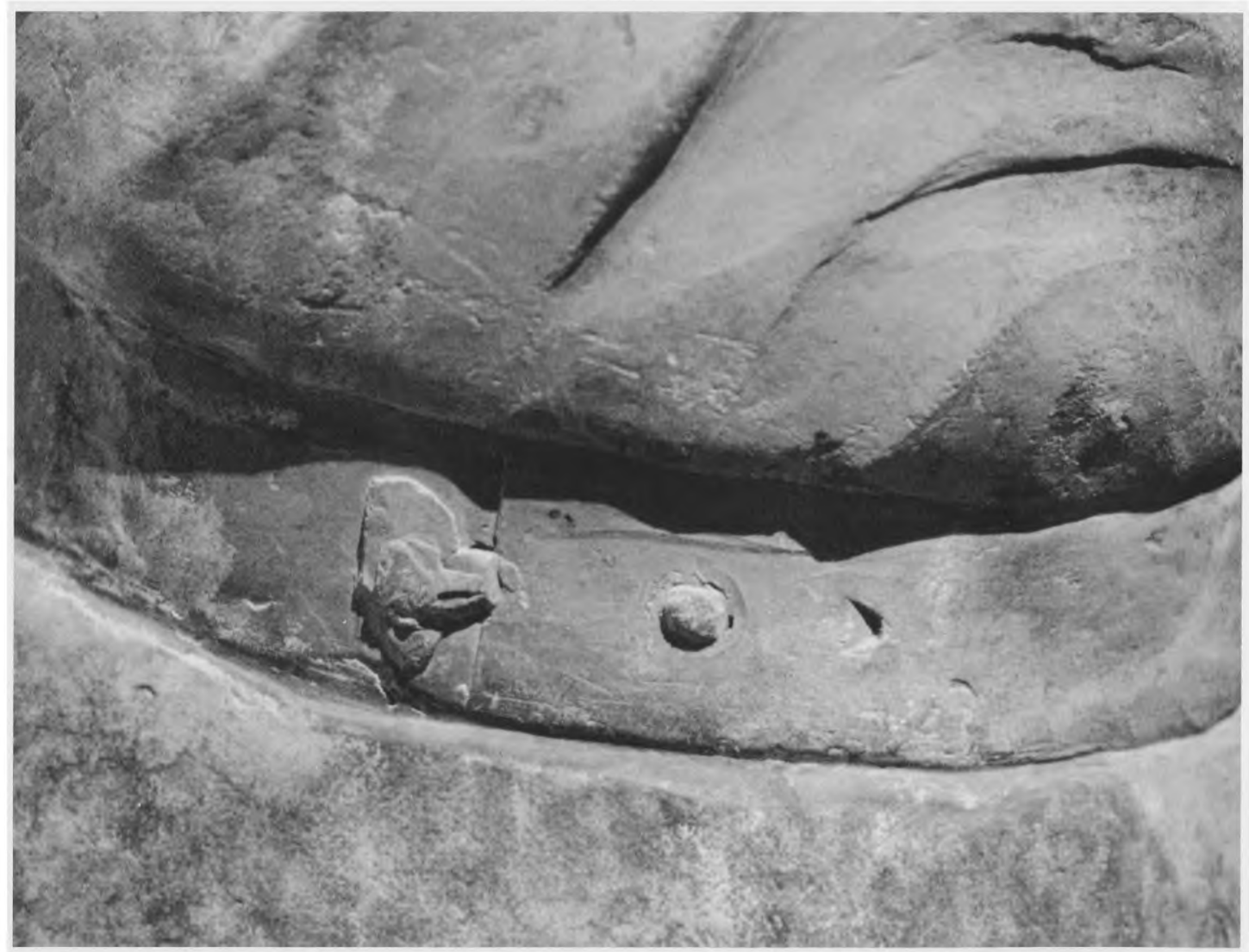

\section{Afbeelding $3 \mathrm{C}$}

Detail gordel van

soldaat nr. 98 uit de aardewerk legers van de

Eerste Keizer van Qin

China, provincie

Shaanxi, Lintong; Qin-

dynastie (221-206

v.Chr.)

foto: Maxwell K. Hearn. Uit: Wen Fong et al.,

The Great Bronze Age of China, New York, 1980, afb. 126 "kledinghaken", waarbinnen de typische lange gordelhaken dan een ondersoort zijn. ${ }^{4}$

\section{Handwerk uit Jin}

Door de associatie met broeken en daarmee ook met paardrijden, is eigenlijk altijd gezegd dat de gordelhaken samen met het gebruik van het paard als rijdier moeten zijn overgenomen van de noordelijke steppevolken, in de tweede helft van de Oostelijke of Late Zhou-dynastie, in de periode van de Strijdende Staten vanaf het eind van de $4^{e}$ eeuw v.Chr. Dat is echter wel de periode waaruit we de grootste aantallen gordelhaken kennen, maar ook graven uit de eerste helft van de Oostelijke Zhou, en zelfs misschien uit de Westelijke of Vroege Zhou, uit de $7^{\mathrm{e}}$ eeuw v.Chr. hebben inmiddels vele gordelhaken opgeleverd - in een puur Chinese omgeving en context, en de vroegste daarvan zelfs zo ver weg van de steppe als maar mogelijk is, in de oostelijke provincie Shandong. ${ }^{5}$

In ieder geval is vastgelegd dat ze niet alleen door mannen maar ook door vrouwen werden gedragen. In het lange vers Zhao hun, de smeekbede aan de ziel van een overleden koning (ca 240 v.Chr., met de in vertaling bekende beginregel "O soul, come back"), waarin de geneugten van het leven aan, hete 
hof van Chu in de $4^{\mathrm{e}}-3^{\mathrm{e}}$ eeuw v.Chr. gedetailleerd worden beschreven, dansen en musiceren de hofdames "in geborduurde kleren van de fijnste zijde":

Twee rijen van acht, perfect in de maat, volvoeren de dans van Zheng;

hun $x i b i$-gespen, handwerk uit Jin, schitteren als stralende zonnen. ${ }^{6}$

Michael Sullivan heeft hierbij gesuggereerd dat de niet-Chinese term xibi mogelijk afgeleid is van een Turks-Mongools woord voor gordelhaak: särbe; ${ }^{7}$ deze en andere aannames van vreemde oorsprong op linguïstische gronden zijn tegenwoordig echter grotendeels verworpen. ${ }^{8}$

Wèl interessant is om te weten dat bij Houma, op de plaats waar zich eens de bronsgieterijen van de staat Jin bevonden, naast gietvormen voor bronsvaten inderdaad hele bergen gietvormen voor gordelhaken zijn aangetroffen: de bron voor het schitterend handwerk uit Jin.

\section{Noten}

1. Het stuk met het inventarisnummer AK-MAK-22 (afb.1) vertoont afdrukken van textiel in het patina rond de knop en bij de haak.

2. Zoals ook eerder in de uitgave van de VVAK en het Rijksmuseum van 1985: Asiatic Art in the Rijksmuseum, Amsterdam, p. 41. Zie ook deze publicatie voor de objectbeschrijving van de twee hier opnieuw getoonde gordelhaken.

3. O.a. in het Rijksmuseum de vergulde haak uit de Westelijke Han, ca 200 v.Chr.-0. (AK-MAK-1463-b) en zie bijvoorbeeld ook Jessica Rawson, Ancient China, Londen, 1980, pl. X, 2e haak van links.

4. Wu Hung, "Art and Architecture of the Warring States Period" in The Cambridge History of Ancient China, Cambridge 1999, p. 697. Voor de term "garment hook" (kledinghaak) verwijst hij naar Thomas Lawton, Chinese Art of the Warring States Period: Change and Continuity, 480-222 B.C., Washington, D.C., 1982.

5. Zie de (helaas niet geannoteerde) serie van het National Museum of Chinese History: A Journey into Chinese Antiquity, Vol.2., Beijing, 1997, p. 167. Zonder bronvermeldingen is het onmogelijk na te gaan op welke opgravingen men hier doelt, maar vgl. ook Wu Hung, op.cit., voor verwijzingen naar gordel- en/of kledinghaken uit de eerste helft van de Oostelijke Zhou (de Lente en Herfst-periode, 770-481 v.Chr.), ook o.a. uit Shandong.

6. (Vertaald uit:) David Hawkes, Ch'u Tz'u, The Songs of the South, Oxford, 1959, p.108.

De staat Chu heerste over een groot gebied rond en ver ten zuiden van de middenloop van de rivier de Yangzi. Zheng was een van de kleinere Strijdende Staten in midden-China die door Chu zijn opgeslokt; Jin was een grote noordelijke staat waar de overblijfselen zijn opgegraven van indrukwekkend grote bronswerkplaatsen (bij Houma, hoofdstad van Jin in de $6^{\mathrm{e}}-5^{\mathrm{e}}$ eeuw v.Chr.).

7. Michael Sullivan, The Arts of China, Berkeley/Londen, 1977, p. 57, n. 2.

8. Jenny So beargumenteert overtuigend de originaliteit van de Chinese gordelhaak door te wijzen op de essentiële verschillen met o.a. het Scythische model, in: Jenny F. So en Emma C. Bunker, Traders and Raiders on China's Northern Frontier, Washington, D.C., 1995, pp. 81-83. 


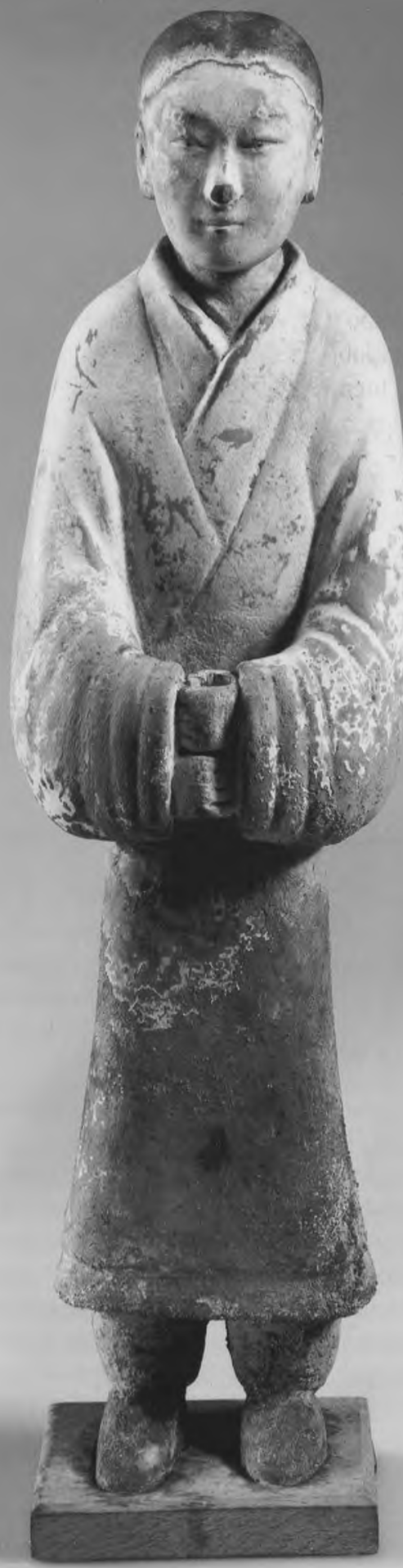

